\title{
Concordâncias/discordâncias acerca do processo inclusivo no Ensino Superior: um estudo exploratório
}

Lígia da Silva Marques*

Cláudia Gomes**

\section{Resumo}

Com objetivo de caracterizar a concordância docente acerca da inclusão no ensino superior de alunos com deficiências, transtornos globais do desenvolvimento e superdotação; bem como a avaliação que os próprios docentes fazem quanto à preparação profissional e institucional necessária a este processo, foram participantes deste estudo 20 professores de uma universidade federal da região sul mineira, que responderam a um questionário sobre a temática investigada. Após analise quantitativa dos dados, obteve-se os seguintes resultados: os professores têm conhecimento da necessidade de se instaurar um cenário inclusivo eficaz na instituição e confirmam a necessidade de preparação física e de funcionários para fazê-lo; porém indicam não se sentirem capacitados para tanto. Em relação à concordância com a inclusão de pessoas com deficiências sensoriais, pôde-se evidenciar que os professores refletem concordância total ou parcial; já no caso de necessidades vinculadas aos distúrbios comportamentais, déficits intelectuais ou deficiências múltiplas, é indicada discordância. Isto parece denotar que quanto maior a necessidade de comprometimentos e ações profissionais diferenciadas, bem como adaptações curriculares e pedagógicas; menor a concordância com a inclusão, principalmente para professores que lecionam na área de Ciências Exatas. Como considerações finais, ressaltamos a necessidade de avançarmos para discussões e práticas educacionais que sustentem a atuação profissional inclusiva, ações estas consideradas pelos docentes participantes do estudo como de suas responsabilidades e competências profissionais e que são concepções alinhadas e propicias para a instauração e/ou fortalecimento de ações que garantam condições atitudinais, pedagógicas e institucionais que embasem a construção de uma universidade com o intuito de garantir acesso, permanência e desenvolvimento à todos os seus alunos.

Palavras-chave: Ensino Superior; Inclusão; Concordância docente.

\footnotetext{
* Licenciada em Química/Licenciatura - UNIFAL-MG. Alfenas, Minas Gerais, Brasil.

** Professora Instituto de Ciências Humanas e Letras - ICHL/UNIFAL-MG. Alfenas, Minas Gerais, Brasil.
} 


\title{
Agreements/disagreements about the inclusive process in Higher Education: an exploratory study
}

\begin{abstract}
With the intention to characterize the teachers agreement about the inclusion of students with deficiencies, global disorders development and giftedness in college; as well as the evaluation that the teachers themselves do as the professional and institutional capacity necessary to this process; this study investigated 20 teachers in a federal university of Minas Gerais, they answered a questionnaire about the investigate thematic. After data quantitative analysis, the following results were obtained: the teachers were aware of the necessity to establish an effective inclusive scene in the institution and confirmed the necessity of physical and employees' preparation to do it; therefore, they didn't feel capable enough to do it. In relation to the concordance of the inclusion of people with sensory deficiencies, it was evident that teachers reflect total or partial agreement; now in case of necessities linked with behaviors disorders, intellectual deficit or multiples deficiency, they disagree. This seems to denote that higher the necessity of commitments and differentiated professional actions, such as pedagogical and curriculum adaptations; less is the agreement with the inclusion, mostly for the teachers who teach in exact science area. As final consideration, we emphasize the necessity to move forward for discussion and educational practices which support the inclusive professional action, considered by the teachers their competence and responsibility; understanding this, which provides the introduction and the fortification of actions that ensure attitudinal, pedagogical and institutional conditions could support the construction a university wirh the intention of providing access, permanence and development to all the students.
\end{abstract}

Keywords: Higher Education; Inclusion; Teacher agreement.

\section{Introdução}

No Brasil, as políticas de inclusão surgiram no final da década de 80 e início dos anos 90. Um breve panorama histórico pode ser apresentado pela promulgação em 1988 da Constituição da República Federativa do Brasil (BRASIL, 1988), assim como pelo Estatuto da Criança e do Adolescente, publicado em 1990 (BRASIL, 1990). No entanto, as discussões ganharam força anos depois, com a promulgação da Lei de Diretrizes e Bases da Educação (BRASIL, 1996).

Recentemente, documentos como a Política Nacional de Educação Especial na Perspectiva da Inclusão (2008), e a promulgação do Decreto n. 7.61l (BRASIL, 2011), são avanços legislativos e legais que amparam a temática da educação inclusiva, na efetivação e reestruturação dos espaços escolares para que sejam atreladas a garantia de acesso, permanência e desenvolvimento de todos os educandos que possuem deficiências, transtornos globais do desenvolvimento, e altas habilidades ou superdotação. 
Assim, uma das discussões centrais que vem ganhando cada vez mais espaço nos debates e ações educacionais no país é a inclusão destes alunos no ensino superior. A presença dos mesmos na graduação é um novo desafio. O processo de construção de um espaço inclusivo na educação, qualquer que seja o seu nível, não se dá por meio de uma padronização; ao contrário, é necessário que a inclusão se faça a partir da experiência e do reconhecimento das diferenças. A participação de pessoas com deficiência, diferentes transtornos ou superdotação em salas de aula pode ser uma contribuição para todos os alunos, ao promover a reflexão sobre as práticas educacionais a partir das questões suscitadas no cotidiano das aulas, o que leva à flexibilização e à reinvenção das mesmas (AINSCOW, POTER, WANG, 1997; SEKKEL, 2003, 2005).

Neste sentido, o espaço universitário é propício para a formação e capacitação do indivíduo, criação, transferência e aplicação de conhecimentos; assim como para o avanço da educação em todas as suas formas e esferas, pois se constitui como um campo importante para a produção, aplicação do conhecimento científico e para o avanço tecnológico em uma sociedade (CASTANHO \& FREITAS, 2005).

Em relação à educação inclusiva no ensino superior, os eixos norteadores da política educacional estão na Política de Inclusão da Pessoa Portadora de Deficiência no Ensino Superior, com destaque para a criação de centros de apoio pedagógico, da viabilização de intérpretes, instrutores de libras, e acesso à comunicação, para promover acessibilidade e formação docente (BRASIL/SESU, 2006).

Para tanto, o grande desafio posto para as universidades é formar educadores que não sejam apenas instrumentos de transmissão de conhecimentos, mas, sobretudo, de novas atitudes frente à diversidade humana. Além disso, devem ser preparados para construir estratégias de ensino e adaptar atividades e conteúdos não só para os alunos considerados especiais, mas para todos os integrantes de sua classe. Cabe às faculdades ou cursos de Educação, também, trabalhar com a formação continuada dos atuais professores (GLAT \& PLETSCH, 2004).

Frente ao exposto, percebe-se que a inclusão é fundamental para a construção de uma sociedade democrática. O respeito às diferenças e a igualdade de oportunidades requer o movimento de incluir, que faz uma ruptura com o movimento da exclusão. Este debate vem sendo promovido por diferentes instâncias e países, incluindo o Brasil. A premissa central que sustenta as discussões é a da garantia à todos do acesso contínuo ao espaço comum na vida em sociedade, que deverá estar organizada e orientada, respeitando a diversidade humana, as diferenças individuais e promovendo igualdade de oportunidades de desenvolvimento para toda a vida (CASTANHO $\&$ FREITAS, 2005).

Assim, a efetivação e implementação da educação inclusiva nos espaços educacionais em nosso país, principalmente nos espaços universitários, exige uma mudança na perspectiva educacional para novos posicionamentos diante dos processos de ensino e aprendizagem; à luz de concepções e práticas mais evoluídas, partindo do principio fundamental do respeito à toda e qualquer diferença ou característica,

Revista Educação Especial | v. 27 | n. 49 | p. 313-326| maio/ago. 2014

Santa Maria 
lançando mão não apenas de reformulação técnica, mas acima de tudo que se reformulem as convicções, os compromissos e as disposições dos educadores. (GOMES \& SOUZA, 2012).

Como citado por Gomes e Gonzalez Rey (2007), quando desviamos nossa atenção da deficiência do aluno e deixamos de vê-la como fator limitante, nos atentamos ao fato que esse aluno é capaz não só de aprender, como de tomar as rédeas de sua vida, com direitos e deveres como todo cidadão. A deficiência nesse ponto cai para segundo plano, e novas relações de convivências sociais e individuais, junto a gradativas melhoras em vários aspectos de sua vida, começam a ser efetivamente possibilitadas.

A educação inclusiva revoluciona todas as políticas educacionais já propostas até hoje, pois o aluno não é excluído ou diferenciado em seu processo de aprendizagem, diferentemente das compreensões anteriores acerca da escolarização de alunos com deficiências. A inclusão causa uma mudança de perspectiva educacional, pois não se limita a incluir somente os alunos que apresentam dificuldades na escola, mas apóia a todos: professores, alunos, pessoal administrativo; para que obtenham sucesso na corrente educativa geral. O impacto desta concepção é considerável, porque ela supõe a abolição completa dos serviços segregados e de exclusão (MANTOAN, 2001).

Porém, para que essa abolição seja mesmo completa, o que não vem acontecendo efetivamente nas realidades escolares, é necessário que instituições e professores assumam o compromisso profissional com a abordagem da diversidade humana, o que depende de um processo de reestruturação e atualização contínua dos espaços e processos que regem as ações escolares e educacionais em nossas instituições. Para tanto, um indicativo central que favorece e polariza este processo de transformação e mudança é a inserção do debate dos postulados da educação inclusiva nos cursos de licenciatura, com a criação de espaços que propiciem formas de reflexão e posicionamentos críticos e construtivos atrelados a defesa de uma escola democrática. (MANTOAN; 2006).

Para Mantoan e Baranauskas (2009), a construção de uma universidade inclusiva depende da criação de espaços institucionais, pedagógicos e acadêmicos que possibilitem movimento, questionamento e transformação a partir das reflexões sobre as condições subjetivas de convívio e sobre a forma como nos relacionamos com as diferenças.

Evidencia-se assim que o processo inclusivo na universidade não pode ser restrito aos métodos e recursos especializados, mas deve propiciar orientação que leve ao desenvolvimento de competências e habilidades, com a oferta de recursos, apoio e políticas institucionais que permitam a exploração e o domínio cada vez mais amplo das ações educacionais, pois este espaço se constitui como polarizador de transformações e reestruturações ideológicas, sociais e humanas.

Frente a tais considerações, este estudo lançou como objetivo caracterizar na concepção de docentes universitários a concordância sobre a inclusão de alunos com deficiência, transtornos globais do desenvolvimento e superdotação no ensino supe- 
rior, assim como a avaliação que fazem quanto ao seu preparo profissional e as condições institucionais necessárias à este processo.

\section{Metodologia}

\section{Participantes}

A pesquisa teve como participantes 20 professores do ensino superior de uma universidade federal da região Sul Mineira. Quanto à caracterização dos participantes, com relação ao gênero, 10 são do sexo masculino e 10 são do sexo feminino, com idades entre 27 e 50 anos, e atuam como docentes em média há 15 anos. Em relação à formação dos professores, 9 (47\%), lecionam na área de Ciências Humanas; 7 (37\%), lecionam na área de Ciências Exatas; e 4 (16\%), lecionam na área de Ciências Biológicas. Destes 20 docentes, 4 possuem cursos de pós-doutorado; 10 possuem cursos de doutorado; 5 possuem mestrados e l é pós-graduado (especialista).

\section{Instrumentos}

Para a coleta dos dados foi utilizado um questionário composto por questões abertas e fechadas, visando caracterizar: formação; atuação profissional; conhecimento da temática inclusiva; preparação continuada e concordância com o processo de inclusão educacional na graduação. Os questionários foram entregues individualmente aos professores participantes do estudo e recolhidos após o prazo de uma semana. Ressalta-se que juntamente com os questionários foram entregues os termos de consentimentos livres e esclarecidos, que firmaram o compromisso ético do estudo.

\section{Análise dos dados}

Os dados obtidos foram analisados quantitativamente por meio de provas estatísticas descritivas, e organizados em tabelas e gráfico sistematizados na análise dos resultados.

\section{Resultados e Discussão}

De modo geral, as pesquisas que discutem os desafios para a educação inclusiva, apontam o debate das condições e atuações dos professores; concluindo que são estes os profissionais que, em sua prática cotidiana, precisam remover os obstáculos que se interpõem entre o aluno e o ensino que lhe é ministrado. Para tanto, os estudos contemplam também a compreensão de que este processo depende de condições institucionais e pedagógicas favoráveis que possibilitem aos docentes a responsabilidade pelo aprendizado de todo e qualquer aluno, modificando seu enfoque de atuação profissional e considerando os alunos dentro de sua individualidade e diversidade; esse sim, é o primeiro passo para a compreensão das práticas inclusivas, assim como a tomada de consciência frente à novas posturas e à sua prática de atuação. (MANTOAN, 2006; OROFINO \& ZANELLO; 1999).

Para tanto, com o interesse de reconhecer os desafios de formação e atuação dos docentes universitários quanto à preparação, foram contemplados os seguintes questionamentos: participação em curso ou palestra sobre a temática educacional in-

Revista Educação Especial | v. 27 | n. 49 | p. 313-326| maio/ago. 2014

Santa Maria 
clusiva; experiência profissional com esta população de alunos; compreensão da responsabilidade e competência nesta atuação profissional; preparação para lidar com alunos com NEE. (Tabela 1).

\begin{tabular}{l|c|c}
\hline Questão & Sim & Não \\
\hline Participação em curso/palestra sobre a temática educacional inclusiva & 9 & 11 \\
Leciona ou já lecionou para alunos em processo de inclusão & 8 & 12 \\
Consideração da responsabilidade e competência no processo inclusivo & 16 & 3 \\
Preparação profissional para a atuação educacional inclusiva & 2 & 18 \\
\hline
\end{tabular}

Tabela 1: Caracterização da formação e preparação profissional na concepção dos docentes entrevistados.

Analisando a questão da participação em cursos/palestras acerca da temática educacional inclusiva, constata-se que, dos 20 professores entrevistados, 11 (55\%), nunca participaram de algum cursou ou palestra sobre a Inclusão Educacional de alunos com NEE; enquanto 9 (45\%), já tiveram alguma participação.

Dentre as áreas nas quais lecionam, os participantes que mais indicaram participação em cursos ou palestras acerca do tema inclusão escolar foram os docentes da área de Humanas, enquanto os que menos indicaram participação são da área de Ciências Biológicas. Evidencia-se assim, que menos da metade dos professores entrevistados têm informações ou conhecimento específico para a atuação profissional nos postulados da educação inclusiva. Dentre os que tiveram essas experiências formativas, a maioria leciona na área de Ciências Humanas, área esta em que o tema da inclusão é necessariamente contemplado. No entanto, o desafio dado, constitui-se em como fazer tais conhecimentos e concepções ressoarem nas outras áreas ou espaços de construção do conhecimento. Discutir educação inclusiva no ensino superior perpassa assim a discussão do ensino e da construção cientifica, política, social e humana da sociedade em que vivemos e na qual esperamos viver.

Já em relação à questão que identifica a experiência profissional com esta população de alunos, pôde-se evidenciar que dos 20 professores entrevistados, 12 (60\%), nunca lecionaram para estes alunos, enquanto 8 (40\%), já o fizeram. Novamente, analisando-se as áreas, os professores que mais indicaram já terem lecionado para alunos com deficiências, transtornos globais do desenvolvimento ou superdotação, foram os docentes da área de Humanas; enquanto na área de Biológicas não houve nenhuma resposta positiva. Nota-se que, enquanto 9 professores participaram de algum curso/ palestra para capacitação, 8 já lecionaram para estes alunos. Fica evidente, assim, que menos de 50\% da amostra atuou com tais alunos. Fato este relevante ao se levar em consideração que a inclusão no ensino superior só tende a crescer, e este é o momento ideal e essencial para falarmos sobre o tema e sobre os paradigmas educacionais que fundamentam e sustentam esta atuação.

De acordo com Mantoan (2006), os professores e educadores devem mudar seu enfoque educacional e passar a ver que todo e qualquer aluno tem um potencial de aprendizagem, respeitando os direitos e diversidades dos mesmos, e assim tornando sua educação satisfatória dentro de suas possibilidades. Entendemos que o espaço 
universitário é propício para as discussões por possibilitar o debate, a implementação e o acompanhamento de novas práticas e ações, no entanto, tais ações devem estar atreladas a uma compreensão efetiva e experienciada, e que não seja mais um espaço de fragmentação teórica e prática, ou de ações escolares marginalizadas e excludentes.

Se tratando da questão sobre responsabilidade e competência profissional acerca da atuação em salas de aula inclusivas, constata-se que dos 20 professores entrevistados, 16 (80\%), consideram ser de sua responsabilidade esta atuação profissional, enquanto $3(15 \%)$, consideram não ter responsabilidade sobre a educação dos mesmos; e 1 (5\%), optou por não responder à pergunta. A área de atuação profissional dos entrevistados que apresentou a menor tendência a assumir responsabilidade sobre a atuação com estes alunos foi à área das Ciências Exatas.

Podemos lançar como questionamento se o fato dos professores da área de Ciências Exatas indicarem não possuírem responsabilidades e competências com a inclusão educacional de tais alunos é uma consideração que pode estar sendo sustentada pela representação social, de que os alunos que freqüentam os cursos de exatas são os "mais inteligentes", e considerar uma atuação profissional inclusiva é romper com esta compreensão e representação presente nesta área do conhecimento.

Para Mantoan e Baranauskas (2006), para que os professores possam assumir sua responsabilidade perante o ensino de alunos em processo de inclusão devem, primeiramente, tomar consciência e assumir novas posturas e novas práticas pedagógicas, enxergando o aluno dentro de sua diversidade e suas possibilidades de aprendizagem, mudando assim seu enfoque de atuação profissional e acabando com as barreiras existentes entre os alunos e sua aprendizagem.

Para tanto, não podemos desconsiderar que a concepção da responsabilidade e competência pode estar sendo embasada pela avaliação do preparo e atuação profissional dos docentes, que dentre os 20 professores entrevistados, 18 (90\%) apontam não terem recebido nenhum tipo de preparação profissional para trabalhar com os alunos em questão. Os dois professores que indicam possuir preparação, como é de se esperar com base nos resultados já apresentados, lecionam na área de Ciências Humanas. Estes dados demarcam o cenário institucional na percepção dos professores, frente aos desafios da criação e manutenção dos espaços formativos em relação à alunos em processo de inclusão. Cabe ressaltar aqui que, além de responsabilidade do próprio professor, como um profissional comprometido com a excelência de seu trabalho; entendemos ser de responsabilidade também da instituição de ensino propiciar à seus docentes espaços de formação continuada, de debates e reflexões acerca das condições, preparo e atuação profissional atrelados aos princípios educacionais inclusivos.

Compreendemos que para que haja a total abolição da exclusão de alunos deve haver um reordenamento das variáveis que sustentam os processos educacionais à luz de modelos e práticas emancipatórias, que devem perpassar, fundamentalmente, a formação dos professores, principalmente de docentes atuantes nas áreas e disciplinas que contemplam os cursos de licenciatura, dado o espaço polarizador de novas atitudes e ações que pode ser configurado neste cenário.

Revista Educação Especial | v. 27 | n. 49 | p. 313-326| maio/ago. 2014

Santa Maria 
Entretanto, defendemos e assumimos que pensar em uma prática educacional inclusiva depende da oferta e manutenção de espaços organizacionais e institucionais que possibilitem a construção de novas concepções e atuações profissionais, questionamentos estes que foram levantados aos participantes e descritos a seguir (Tabela 2):

\begin{tabular}{l|c|c}
\hline Questões & Sim & Não \\
\hline Conhecimento de alunos em processo de inclusão na universidade & 13 & 7 \\
$\begin{array}{l}\text { Avaliação do preparo docente para a atuação com alunos em processo de inclusão na } \\
\text { universidade }\end{array}$ & 0 & 20 \\
$\begin{array}{l}\text { Consideração da preparação profissional de técnicos e funcionários da universidade } \\
\text { para lidar com alunos em processo de inclusão }\end{array}$ & 0 & 20 \\
$\begin{array}{l}\text { Avaliação da necessidade da universidade ofertar espaços formativos para o processo } \\
\text { de educação inclusiva }\end{array}$ & 19 & 0 \\
\hline
\end{tabular}

Tabela 2: Avaliação das condições inclusivas dentro da universidade na concepção dos professores entrevistados

Em relação ao conhecimento dos participantes de alunos com deficiências, transtornos globais do desenvolvimento ou superdotação freqüentando a universidade, constatou-se que, dos 20 professores entrevistados, 13 (65\%) não conhecem nenhum processo de inclusão escolar ofertado a estes alunos, e somente 7 (35\%), apontam tal conhecimento. Com base nestes resultados podemos evidenciar uma contradição: a maior parte dos professores que relatou conhecer tais alunos cursando a universidade são da área de Ciências Exatas, justamente a área que menos considera ter responsabilidade sobre a educação dos mesmos. Cabe então uma pergunta: falta somente preparação (cursos, debates, recursos, práticas pedagógicas) para estes professores lidarem com alunos em processo de inclusão ou falta primariamente uma reflexão de concepções educacionais mais democráticas? Como o grupo de professores que não se considera responsável pelo processo educacional inclusivo pode ser o grupo que mais indica conhecer alunos neste processo? E assim, que tipos de representações vêm sustentando suas práticas em relação à educação inclusiva no ensino superior?

Para Castanho \& Freitas (2005), o Ensino Superior é um espaço de extrema importância na formação e capacitação do indivíduo e, entre outras coisas, permite o desenvolvimento da capacidade de criar, bem como o aprendizado e a transferência do conhecimento. Assim, para se pensar a construção de uma relação pedagógica inclusiva, com premissas e ações mais justas e igualitárias além do ingresso (como já garantido por lei); entende-se como premissa que, além do reconhecimento destes alunos no espaço universitário, é urgente a compreensão de suas necessidades.

Assim, quando questionados se receberam algum tipo de preparação profissional para a atuação com esta população de alunos, todos os docentes participantes indicam que a universidade não oferece ações de preparação profissional que favoreçam a prática pedagógica com alunos em processo de inclusão. Ainda em relação à formação de técnicos e funcionários, os professores participantes de forma unânime indicam que estes profissionais não estariam preparados para atuar com estes alunos. 
No entanto, fato relevante é indicado com base nos resultados em relação à valorização que os docentes atribuem aos espaços formativos a serem ofertados. $\mathrm{Na}$ concepção de 19 (95\%) dos docentes participantes a instituição universitária deveria propor e estabelecer espaços de formação e preparação para a atuação docente com alunos em processo de inclusão escolar.

Frente a esses resultados, questionamentos se fazem necessários: como pensar em um ambiente inclusivo se os próprios professores, na avaliação dos mesmos; e os demais profissionais da universidade não vivenciam na instituição cenários formativos efetivos para a discussão do processo de inclusão de alunos com deficiências, transtornos globais do desenvolvimento ou superdotação? Porém, os mesmos docentes indicam a pré-disposição no desenvolvimento de tais espaços, fato este de importância central para o debate institucional. Entendemos que a sociedade em si e a comunidade educativa caminham cada vez mais rápido para a equalização do ensino, e torna-se indispensável que todo e qualquer órgão em suas mais variadas instâncias que lidem com a educação participem dessa efetivação. Em relação às analises tecidas, não podemos desconsiderar as ações que por ventura já tenham sido desenvolvidas e instauradas no contexto estudado; no entanto, o que é deflagrado na concepção dos professores informantes deste estudo, é a ânsia de que tais espaços devam ocorrer ou ainda ser dimensionados e/ou transformados m espaços formativos cotidianos.

Entendemos que a mudança educacional deve ser feita em nosso país para que a efetivação da educação inclusiva aconteça de fato. As concepções, os compromissos e os posicionamentos dos educadores têm que ser mudados, partindo do princípio fundamental de respeito à todos, com a valorização do espaço escolar justo e democrático, para que suas práticas pedagógicas evoluam e as políticas necessárias possam então ser implementadas.

Fica evidente com a resposta a esta questão que a maioria absoluta dos professores tem compreensão de que é necessário e que não se pode mais adiar a inclusão educacional no ensino superior. Mesmo que alguns ainda tenham certa resistência ao lidar com o tema, mostram possuir o entendimento que o novo modelo de escola caminha para a equalização da educação, e que, se não aceitarem e não se adaptarem a isso, ficarão desajustados à esse novo modelo. Citando novamente Mantoan (2006), em todas as escolas do mundo onde o processo de inclusão funcionou, o primeiro passo sempre foi a mudança na formação e nas concepções dos professores. Estes, cientes e alinhados aos pressupostos e paradigmas inclusivos, são o primeiro degrau para que esta escada seja construída; e a reestruturação do espaço físico escolar e as condições de atuação da administração e funcionários das escolas, se dão como conseqüências deste fato.

Claro que esta preparação não deve se restringir aos métodos e recursos especializados, mas sim propiciar orientação que leve ao desenvolvimento de competências e habilidades, que permitam a exploração e o domínio cada vez mais amplo das práticas profissionais em suas diferentes esferas (pedagógicas e técnicas). No entanto, o redirecionamento dessas práticas e ações só poderão ser traçadas tanto nas condições estruturais, como organizacionais e institucionais, quando revisitarmos as

Revista Educação Especial | v. 27 | n. 49 | p. 313-326| maio/ago. 2014

Santa Maria 
premissas das concordâncias ou discordâncias sobre o processo inclusivo no contexto de educação superior, como descrito no gráfico a seguir:

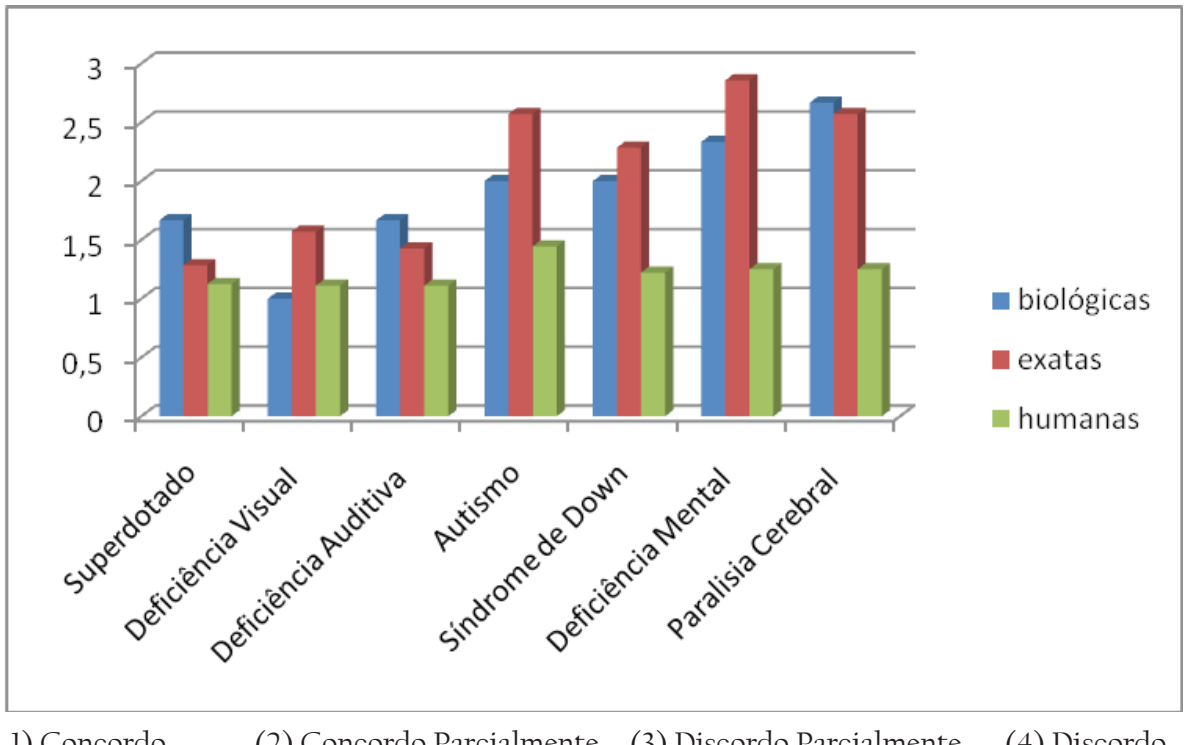

1) Concordo

(2) Concordo Parcialmente

(3) Discordo Parcialmente

(4) Discordo

Gráfico 1: Discordância dos professores entrevistados quanto à inclusão no ensino superior de alunos com diferentes tipos de deficiência, dividido por área de atuação.

Analisando-se o Gráfico 1 quanto as concordâncias sobre o processo de inclusão escolar de alunos com deficiências, transtornos globais do desenvolvimento e superdotação, pôde-se evidenciar que para Deficiência Visual, Síndrome de Down, Autismo e Deficiência Mental os professores da área de Exatas se mostraram mais discordantes. Já para Superdotação, Deficiência Auditiva e Paralisia Cerebral, os professores da área de Ciências Biológicas foram mais discordantes. Os professores da área de Ciências Humanas se mostraram mais concordantes para todos os quadros questionados.

Entendemos que a concordância ao processo inclusivo pelos professores da área de Ciências Humanas, assim como a discordância exacerbada da área de Ciências Exatas, estão vinculadas as especificidades das respectivas formações acadêmicas; de um lado, acredita-se e espera-se que, desde suas graduações, os profissionais vinculados as áreas humanas sejam acostumados e apresentados às idéias de inclusão, desenvolvendo assim o entendimento necessário; além, é claro, de atuarem em uma área central de debates e ações para a equalização do ensino.

Por outro lado, as Áreas de Ciências Exatas encontram-se mais distantes do debate educacional e social inclusivo. No entanto, o que se mostra constante na avaliação da concordância/discordância dos docentes é que quanto maior a necessidade e o comprometimento de ações profissionais diferenciadas, além de adaptações curriculares e pedagógicas para a inclusão dos alunos indicados, menor a concordância com o processo no ensino superior. 
Assim, compreendemos que efetivar a educação inclusiva de alunos com deficiências, transtornos globais do desenvolvimento e superdotação esbarra, prioritariamente, na resistência da construção de novas representações para alunos em processo de inclusão. Assim como tais resistências parecem sustentar sentimentos ambíguos quando se trata do processo em questão, esta resistência pode (e frente aos dados anteriores apresentados na pesquisa, efetivamente está) sustentando atitudes e sentimentos negativos para com os alunos neste processo, mesmo quando a maioria dos docentes aponta a compreensão e importância profissional de suas ações neste processo (CARMO NETO, 2000; TESARO, 2004).

\section{Considerações finais}

Este estudo buscou caracterizar a concordância acerca da inclusão de alunos com deficiências, transtornos globais do desenvolvimento e superdotação no ensino superior na perspectiva de docentes universitários; assim como a avaliação que fazem quanto à preparação profissional e as condições institucionais necessárias à este processo. Não nos propomos a quaisquer generalizações, nem tampouco avaliar as ações políticas e institucionais da universidade em que os participantes atuam, centramonos no objetivo de apenas entender as avaliações e apontamentos dos informantes da pesquisa.

Evidenciamos, com base nos resultados e na perspectiva dos participantes, a falta de preparação e formação específica para a atuação com alunos em processo de inclusão no ensino superior, uma avaliação insatisfatória quanto aos aspectos organizacionais e formativos ofertados pela universidade quanto a temática. No entanto, deve ser ressaltado que de forma significativa os professores participantes apontam concordância quanto à concepção de responsabilidade e competência em atuar com esta população de alunos na graduação, fato este que evidencia possibilidades positivas de debates e avanços em relação ao tema.

Assim, mesmo indicando pré-disposição para firmarem o debate inclusivo, pôde-se evidenciar a resistência de algumas áreas em relação à inclusão dos alunos em questão, sendo maior a discordância com as deficiências relacionadas aos déficits cognitivos e comportamentais.

Lançamos assim como questionamentos finais se as discordâncias dos professores não estariam relacionadas à necessidade de uma reestruturação de suas práticas docentes, bem como de seus métodos avaliativos e do ambiente educacional. O aluno contemplado pelas políticas educacionais inclusivas foge ao estereótipo de aluno com que o professor universitário está acostumado a lidar, social, física e cognitivamente. Para atuar com estes alunos seria necessário não só adaptar seus materiais e métodos, mas repensar e construir novas estratégias de ensino efetivamente inclusivas e que garantam além do acesso do aluno ao ensino superior, a permanência e o desenvolvimento do mesmo. Para tanto, entendemos como central o compromisso da Universidade com a abordagem da temática e com a criação de espaços de reflexões e discussões, que favoreçam a construção de novas dinâmicas e concepções educacionais favorecedoras de uma sociedade democrática. 


\section{Referências}

AINSCOW, M.; PORTER, G.; WANG, M. Caminhos para as Escolas Inclusivas. Lisboa: Instituto de Inovação Educacional, 1997.

BLANCO, R. et al. Aprendendo na diversidade: implicações educativas. Conferência apresentada no III Congresso Ibero-americano de Educação Especial. Foz do Iguaçu, PR, 2005.

BRASIL. Diário Oficial da União. Estatuto da Criança e do Adolescente. (Brasil, 8.069/90). Brasília, DF, 1990.

BRASIL. Decreto № 7.611, de 17 de novembro de 2011. Dispõe sobre a Educação Especial, o Atendimento Educacional Especializado e outras providências. Brasília: MEC, 2011.

BRASIL. Ministério da Educação e Cultura. Lei de Diretrizes e Bases da Educação. Brasília, DF, 1996.

BRASIL. Ministério da Educação. Política Nacional de Educação Especial na Perspectiva da Inclusão. Brasília, DF, 2008.

BRASIL. Ministério da Educação. Secretaria de Educação Superior. Brasília, DF, 2006.

BRASIL. Senado. Constituição da República Federativa do Brasil. Brasília, DF, 1998.

CARMO N. H. Percepções de educadores quanto à inclusão e integração de crianças e jovens com necessidades especiais. Dissertação de mestrado - não publicada. Pontifícia Universidade Católica de São Paulo. Psicologia da Educação, 2000. 10lp.

CASTANHO, D. M; FREITAS, S.N. Inclusão e prática docente no ensino superior. Revista do Centro de Educação. Edição 2005 (N. 27). Santa Maria, RS, 2005.

GLAT, R.; PLESTCH, M.D. O Papel da Universidade Frente às Políticas Públicas para Educação Inclusiva. Revista Benjamim Constant. Edição 10, (N. 29). Rio de Janeiro, RJ, 2004. p. 3-8.

GODOY, E. A. et al. A Cartilha: Acesso de Pessoas com Deficiência as Classes e Escolas Comuns da Rede Regular de Ensino. São Paulo, 2002.

GOMES, C.; GONZALEZ REY, F. Inclusão Escolar: Representações Compartilhadas de Profissionais da Educação Acerca da Inclusão Escolar. Revista Psicologia: Ciência e Profissão. V. 27, (N. 3). Brasília, DF, 2007.

GOMES, C.; SOUZA, V. L. T. Psicologia e inclusão escolar: reflexões sobre o processo de subjetivação de professores. Revista Psicologia: Ciência e Profissão (Impresso), v. 32, p. 1, 2012.

MANTOAN, M. T. E. Inclusão Escolar: O que é? Por quê? Como fazer? São Paulo: Editora Moderna. 2006.

MANTOAN, M. T. Todas as Crianças São Bem-Vindas à Escola. Universidade Estadual de Campinas / UNICAMP - Laboratório de Estudos e Pesquisas em Ensino e Reabilitação de Pessoas com Deficiência Campinas, SP, 2001. (manuscrito)

MANTOAN, M. T. E; BARANAUSKAS, M. C. C. Atores da Inclusão na Universidade - Formação e Compromisso. UNICAMP - Biblioteca Central Cesar Lattes, Campinas, SP, 2009.

OROFINO, A. M.; ZANELLO, V. A. A Subjetividade Social na Escola. Revista Brasileira de Educação Especial. Brasília: Paralelo, 1999.

SEKKEL, M. C. A Construção de um Ambiente Inclusivo na Educação Infantil: Relato e Reflexão sobre uma Experiência. Tese de doutorado em Psicologia. Universidade de São Paulo, São Paulo, 2003.

TESSARO, N. S. Inclusão Escolar: concepções de professores e alunos da educação regular e especial. Tese de Doutorado - não publicada. Pontifícia Universidade Católica de Campinas. São Paulo, 2004. 208 p. 


\section{Correspondência}

Claudia Gomes - Universidade Federal de Alfenas, Conselho de Ensino, Pesquisa e Extensão. Rua Gabriel Monteiro da Silva, Centro, CEP: 37130-000 - Alfenas, Minas Gerais - Brasil.

E-mail: cg.unifal@gmail.com

Recebido em 30 de abril de 2013

Aprovado em 12 de julho de 2013

Revista Educação Especial | v. 27 | n. 49 | p. 313-326| maio/ago. 2014

Santa Maria

Disponível em: <http://www.ufsm.br/revistaeducacaoespecial> 
